\title{
HUBUNGAN KEKERABATAN BAHASA MELAYU RIAU DAN DIALEK AKIT (SEBUAH PENDEKATAN HISTORIS)
}

\author{
Mohd. Fauzi, Dwi Widayati \\ Universitas Lancang Kuning, Pekanbaru \\ Universitas Sumatera Utara, Medan \\ mohd.fauzi_007@yahoo.co.id
}

\begin{abstract}
The research attempted to describe the kinship relationship between Riau Malay language and Akit dialect, a historical approach. This research was conducted in Padang Island, Kepulauan Meranti regency, using 200 Swadesh's basic vocabulary as an analytical material, both lexicon equations were found about $80 \%$ by comparison of identical. The method used was descriptive-qualitative. The data was collected by using cakap method and simak method. The data analysis applies agih method with deletion technique, substitution technique. The data used was spoken language. The data was collected by using questionnaire, interviews, observation, and intuition methods. The source of data was Malay language Akit dialect. The result of the research showed that even though there are $80 \%$ similarities of both languages but there are some Akit words that still different from Malay language. These vocabularies must be preserved if it will not be lost in time since they are familiar with technology, many of their vocabularies are no longer used and they tend to use the Malay vocabularies.
\end{abstract}

Keywords: Kinship relationship, Dialect, Akit and words

\section{Pendahuluan}

Bahasa Melayu Riau adalah bahasa yang digunakan oleh masyarakat Riau, Melayu daratan dan Melayu Pesisir. Melayu daratan adalah komunitas masyarakat Melayu yang tinggal di daratan sedangkan Melayu pesisir mendiami tepian laut atau pulau-pulau di provinsi Riau. Uniknya adalah orang suku Akit yang tinggal di Kepulauan Meranti, bahasa yang mereka gunakan digolongkan kedalam bahasa Melayu karena dari lebih dari 80 persen kosa kata yang 
mereka miliki dan dipraktekkan dalam kehidupan sehari-hari mirip dengan bahasa Melayu. Fenomena kebahasaan seperti ini perlu diteliti agar lokal genius yang menjadi ciri khas Akit tidak punah.

Penelitian yang sudah dilakukan tentang bahasa Melayu Riau antara lain; (1) Hasan dkk,(1983) "Morfologi dan Sintaksis Bahasa Melayu Riau"; (2) Dahlan, dkk (1985) "Pemetaan Bahasa Melayu Riau dan Jambi”; (3)Tambusai (2016) “Tipologi Morfologis dan Struktur Argumen bahasa Melayu Riau”, (4) Martius (2012) “ Studi Gejala Fonemis antara Bahasa Melayu Riau Dialek Kampar dan Bahasa Indonesia (Sebuah Pendekatan Historis)" dan (5) Riswara (2015) "Inovasi Fonologis Denasalisasi dalam Isolek Bonai Ulakpatian";(6) Widayati (2018) "Hubungan Kekerabatan Bahasa Nias dan Bahasa Sigulai. Dari Pengamatan penulis belum ada yang meneliti hubungan kekerabatan bahasa Melayu Riau dengan Bahasa Melayu Dialek Akit.
Orang Akit di Kepulauan Meranti sebenarnya memiliki kosakata sendiri yang tidak dijumpai di dalam bahasa Melayu Daratan maupun Melayu pesisir, tetapi lama-kelamaan kosakata mereka tergerus perlahan-lahan karena pengaruh bahasa Melayu yang sangat kuat dan juga kehidupan mereka di samping pengaruh kemajuan teknologi. Pada saat ini mereka sudah mengenal listrik dan televisi, handphone dan berbagai peralatan modern yang menyebabkan mereka beradaptasi dengan dunia modern. Mata pencarian mereka pun saat ini tidak lagi berburu atau mencari ikan di laut karena hutan pun sudah tidak menyimpan binatang atau hewan-hewan lagi karena sudah dijamah oleh manusia. Laut yang dahulunya menghasilkan banyak ikan, saat ini tidak lagi seperti dahulu, sehingga mereka harus mencari pekerjaan lain.

Tujuan penelitian ini adalah (1) mendeskripsikan hubungan kekerabatan bahasa Melayu Riau 
Jurnal Ilmu Budaya, Vol. 16, No. 1 Agustus Tahun 2019

selanjutnya disebut (BMR) dan

Bahasa Melayu Dialek Akit selanjutnya disebut (BMDA); (2) mendeskripsikan perbedaan morfologis maupun fonologis bahasa Melayu Dialek Akit dan bahasa Melayu Riau. Peneliti sangat tertarik mengkaji hubungan kekerabatan bahasa ini karena ingin mengangkat bahasa Akit yang dikelompokkan menjadi bahasa Melayu Riau, sedangkan dalam sisi lain masih banyak kosa kata yang mereka miliki berbeda dengan bahasa Melayu.

\section{Konsep}

Teori yang digunakan dalam penelitian ini adalah Linguistik Historis Komparatif. Meskipun memiliki kosa kata sendiri, bahasa orang Akit di Kabupaten Kepulauan Meranti termasuk ke dalam bahasa Melayu Riau karena lebih dari $80 \%$ kosa katanya mirip sehingga bahasa orang Akit ini di sebut dialek Melayu Akit. Pada umumnya, bahasa-bahasa yang berkerabat memiliki ciri-ciri bentuk dan makna yang sama. (cognate set). Perangkat kata kerabat itu dihipotesiskan berasal dari protobahasa yang sama dan dihipotesiskan juga sebagai cikal bakal bahasa-bahasa itu. Kesamaan dan kemiripan bentuk dan makna itu bukan karena pinjaman dan bukan pula karena kebetulan, melainkan karena meneruskan ciri-ciri asali yang sama (protolanguage). Selain itu, di dalam perangkat kata kerabat itu tersimpan pula kesepadanan bunyi yang teratur pada setiap posisinya. Keteraturan itu oleh kaum Neogrammarian disebut sebagai Hukum Bunyi. Hukum bunyi yang terkenal adalah hukum Grimm dan hukum Verner. Hukum Grimm merupakan hukum kesepadanan bunyi bahasa-bahasa Indo-Eropa, sedangkan hukum Verner merupakan hukum kesepadanan bunyi bahasa-bahasa Indo-German (Bynon, 1979; Jeffers and Lehiste, 1979; Hock, 1988). Hubungan bahasa-bahasa yang berkerabat dalam kajian komparatif, pada prinsipnya dapat dibuktikan berdasarkan unsur warisan dari 
bahasa induk atau protobahasanya. Analisis data dilakukan dengan metode historis komparatif. BMR dan BMDA Sigulai dibandingkan secara deskriptif komparatif. Perbandingan secara deskriptif adalah untuk menemukan perubahan-perubahan pada bahasa kerabat yang masih digunakan saat ini oleh penuturnya. Perangkat kata kerabat (cognat set) dibandingkan dengan cara memilih bentuk yang berhubungan dan mengabaikan bentuk yang tidak berhubungan, karena bentuk yang tidak berhubungan, baik bentuk dan maknanya, diasumsikan berasal dari etimon yang berbeda. Artinya, glos yang tidak diperhitungkan adalah kata-kata pinjaman, kata jadian (bukan kata dasar). Dari perangkat kata kerabat (cognat set) yang telah dibandingkan tersebut dihitung jumlah bentuk yang memiliki persamaan dan korespondensi bunyi untuk menetapkan tingkat kekerabatan dan waktu pisah BMR dan BMDA. Bahasa yang diperbandingkan dalam leksikostatistik ini harus mengacu pada bahasa yang berasal dari protobahasa yang sama tanpa mempertimbangkan seberapa jauh jarak kedua bahasa tersebut. Penetapan bahwa kata itu berkerabat adalah dengan (1) Pasangan yang dibandingkan itu identik, (2) Pasangan itu memiliki korespondensi fonemis, (3) Hanya ada satu fonem yang berbeda. Untuk penghitungan leksikostatistik itu digunakan rumus: $\mathrm{C}=\mathrm{k} / \mathrm{n} \times 100 \% . \mathrm{K}$ adalah kata yang berkerabat dan $\mathrm{n}$ adalah jumlah kata yang dibandingkan. Selanjutnya, dihitung waktu pisah dari bahasa yang dibandingkan, dengan rumus: $\mathrm{t}=\log \mathrm{c} / 2 \log \mathrm{r}$. $\mathrm{T}$ adalah waktu pisah, $\mathrm{r}$ adalah daya tahan kosa kata.

\section{Metodologi Penelitian}

Berdasarkan tujuan penelitian ini yakni mendeskripsikan hubungan kekerabatan BMR dan BMDA, dan teori yang digunakan adalah Linguistik Historis Komparatif. Jenis penelitian ini adalah 


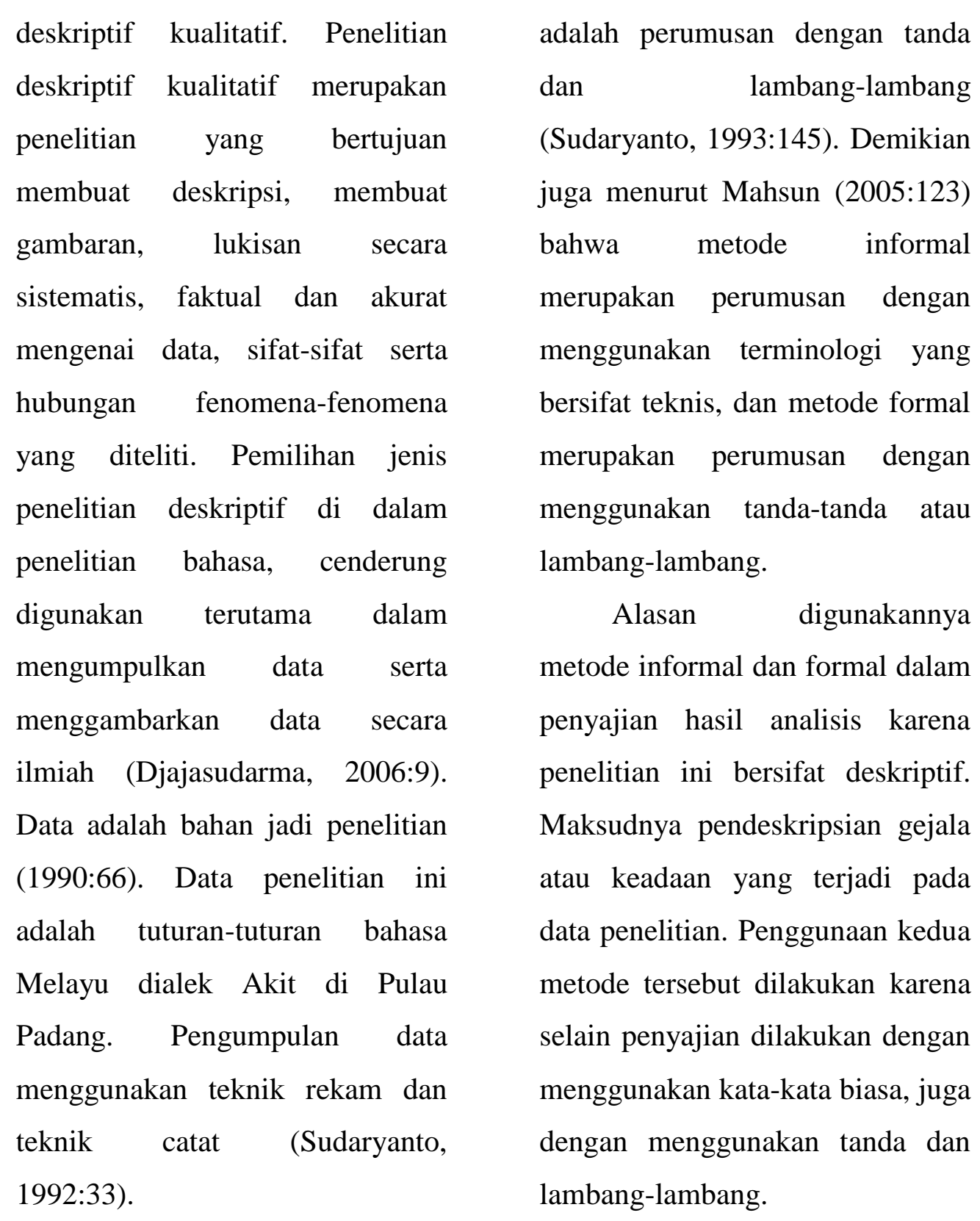

Penyajian hasil analisis data dalam penelitian ini dilakukan dengan menggunakan metode informal dan formal. Penyajian informal berupa rumusan dengan menggunakan kata-kata biasa, sedangkan penyajian formal

\section{Pembahasan}

Hubungan kekerabatan BMR dan BMDA dikaji dan dideskripsikan dengan mengggunakan kosa kata dasar swadesh, yaitu 200 kosa kata 
Jurnal Ilmu Budaya, Vol. 16, No. 1 Agustus Tahun 2019

dasar. Penggunaan Swadesh

dipilih karena sudah menjadi

standar dalam penelitian linguistik

dan hasilnya dapat dipercaya.

Hasil perbandingan dipaparkan

dalam tabel berikut:

\begin{tabular}{|c|c|c|c|c|}
\hline No & $\begin{array}{l}\text { Kata } \\
\text { Dasar }\end{array}$ & $\begin{array}{c}\text { Bahasa } \\
\text { Melayu } \\
\text { Dialek } \\
\text { Akit }\end{array}$ & Inggris & Proto \\
\hline 1 & abu & abu? & ash & 'abu' \\
\hline 2 & air & Aier & water & wayer \\
\hline 3 & akar & ako? & root & aka \\
\hline 4 & $\mathrm{aku}$ & aku? & $\mathrm{i}$ & aku \\
\hline 5 & alir (me) & Halir & to flow & aliy \\
\hline 6 & anak & ana? & child & budak \\
\hline 7 & angin & ałen & wind & balin \\
\hline 8 & anjing & kuyuk & dog & asu \\
\hline 9 & apa & ape? & what & apa \\
\hline 10 & api & api & fire & api \\
\hline 11 & apung & apon & to float & hañut \\
\hline 12 & asap & asep & smoke & hat'ap \\
\hline 13 & awan & awatn & cloud & avon \\
\hline 14 & pagaiman & cem mane? & how & kua \\
\hline 15 & baik & bagos & good & baik \\
\hline 16 & bakar & bako & to burn & tunu \\
\hline 17 & palik & balik & turn & puter \\
\hline 18 & banyak & banyak & many & dakel \\
\hline 19 & bapak & bapa? & father & bapa' \\
\hline 20 & paring & $\begin{array}{l}\text { lepak/tenok- } \\
\text { tenok }\end{array}$ & to lie & hinep \\
\hline 21 & baru & baRu? & new & bayu \\
\hline 22 & basah & baseh & wet & basaq \\
\hline 23 & batu & batu? & stone & batu' \\
\hline 24 & beberapa & beberape? & some & tenah \\
\hline 25 & $\begin{array}{l}\text { belah ( } \\
\text { me ) }\end{array}$ & blah & to split & belah \\
\hline 26 & benar & betol & correct & bener \\
\hline 27 & benih & biji? & seed & beniq \\
\hline 28 & bengkak & benak & to swell & 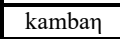 \\
\hline 29 & berenang & berenaךk & swim & lanuy \\
\hline 30 & berjalan & bejalen & to walk & mua-jajala \\
\hline 31 & perat & berat & heavy & beRat \\
\hline 32 & beri & kasi & to give & kasi \\
\hline 33 & besar & besa & big & raya \\
\hline 34 & bilamana & cemmane & how & kua \\
\hline 35 & binatang & binata & animal & $\begin{array}{c}\mathrm{bi}(\mathrm{nN}) \mathrm{a}(\eta)( \\
\mathrm{Ci}) \mathrm{a \eta}\end{array}$ \\
\hline 36 & bintang & bintan & star & binta \\
\hline 37 & buah & bueh & fruit & bu'ah \\
\hline 38 & bulan & bulen & moon & bulan \\
\hline 39 & bulu & bulu? & feather & bulu \\
\hline 40 & bunga & bune & flower & buna \\
\hline 41 & bunuh & munuh & to kill & bunuh \\
\hline 42 & buru & buRu & to hunt & buru \\
\hline
\end{tabular}

\begin{tabular}{|c|c|c|c|c|}
\hline 43 & buruk & burok & bad & jahat \\
\hline 44 & burung & burupk & bird & bujū \\
\hline 45 & busuk & busok & rotten & buruk \\
\hline 46 & cacing & cacin & worm & ulad \\
\hline 47 & cium & cium & to smell & ciyum \\
\hline 48 & cuci & basoh & to wash & basuq \\
\hline 49 & daging & dagink & meat & dagi \\
\hline 50 & dan & same & and & dan \\
\hline 51 & danau & danaw & lake & danaw \\
\hline 52 & darah & daRah & blood & dayah \\
\hline 53 & datang & sampe & to come & daten \\
\hline 54 & daun & daon & leaf & dahun \\
\hline 55 & debu & debu? & dust & 'abuk \\
\hline 56 & dekat & deket & near & hampir \\
\hline 57 & dengan & Same & with & ma \\
\hline 58 & dengar & denge & to hear & denar \\
\hline 59 & di dalam & dalem & in & dalem \\
\hline 60 & di, pada & pade? & at & qi \\
\hline 61 & dimana & dimana? & where & pal \\
\hline 62 & dingin & sejuk & cold & dipin \\
\hline 63 & diri (ber) & tegak & to stand & diri? \\
\hline 64 & di sini & di sika? & here & $\operatorname{di}(n n) i$ \\
\hline 65 & di situ & di sika? & there & hanaa \\
\hline 66 & dorong & tulak & to push & tulak \\
\hline 67 & dua & due? & two & duwa \\
\hline 68 & duduk & duduk & to sit & dukDuk \\
\hline 69 & ekor & iko? & tail & ikuy \\
\hline 70 & empat & empat & four & pat \\
\hline 71 & engkau & kaw & you & kaw \\
\hline 72 & gali & gali & to dig & kali \\
\hline 73 & garam & garem & salt & $\operatorname{asin}$ \\
\hline 74 & garuk & garuh & scratch & garuk \\
\hline 75 & gemuk & gemuk & fat & menak \\
\hline 76 & gigi & gigi & tooth & gigi' \\
\hline 77 & gigit & gigit & to bite & 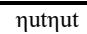 \\
\hline 78 & gosok & gusok & to rub & gusuk \\
\hline 79 & gunung & gunon & mountain & gunuq \\
\hline 80 & hantam & titik & hit & palu \\
\hline 81 & hapus & padam & to wipe & qapus \\
\hline 82 & hati & ati & liver & hatay \\
\hline 83 & hidung & iduๆk & nose & ?idung \\
\hline 84 & hidup & idup & to live & quDip \\
\hline 85 & hijau & ijo & green & hid'av \\
\hline 86 & hisap & isep & suck & susu \\
\hline 87 & hitam & item & black & ?item \\
\hline 88 & hitung & itung & to count & hitun \\
\hline 89 & hujan & ujen & rain & hujan \\
\hline 90 & hutan & utan & forest & utan \\
\hline 91 & ia & die? & him/her & ia \\
\hline 92 & ibu & ma? & mother & 'ibu' \\
\hline 93 & kan & ikan & fish & ikan \\
\hline 94 & kat & ikat & to tie & 'ikat \\
\hline 95 & isteri & bini & wife & binay \\
\hline 96 & ini & ika? & this & 'ini' \\
\hline 97 & tu & Itu & that & itu \\
\hline 98 & jahit & njait & to sew & d'ahit \\
\hline 99 & jalan & jalen & road & jalan \\
\hline 100 & jantung & janton & heart & d'antuך \\
\hline 101 & jatuh & jatoh & to fall & hempas \\
\hline 102 & jauh & Jaoh & far & jawuh \\
\hline 103 & kabut & kabot & fog & kabut \\
\hline 104 & kaki & kaki & foot & kakI' \\
\hline 105 & kalau & kalaw & if & pe \\
\hline
\end{tabular}


Jurnal Ilmu Budaya, Vol. 16, No. 1 Agustus Tahun 2019

\begin{tabular}{|c|c|c|c|c|c|c|c|c|c|}
\hline 106 & kami, kita & kami, kita? & we & kIta & 162 & pusar & pusat & navel & (m)pusèr \\
\hline \multirow[t]{2}{*}{107} & \multirow[t]{2}{*}{ kamu } & \multirow[t]{2}{*}{ kaw } & \multirow{2}{*}{$\begin{array}{c}\text { you (singula } \\
\text { r) }\end{array}$} & \multirow[t]{2}{*}{ kaw } & 163 & putih & puteh & white & putih \\
\hline & & & & & 164 & rambut & rambut & hair & bulu \\
\hline 108 & kanan & kanan & right & wanan & 165 & umput & rumput & grass & rumput \\
\hline 109 & karena & sebab & because & kwalana & 166 & satu & satu & one & esa \\
\hline 110 & kata (ber) & cakap & to say & kunu & 167 & Sayap & sayep & wing & kIpas/kiBes \\
\hline 111 & kecil & keci? & small & & 168 & sedikit & sikit & few & \begin{tabular}{|c|} 
dikih \\
\end{tabular} \\
\hline 112 & kelahi & gadoh & to fight & haduh & 169 & siang & petan & afternoon & \\
\hline 113 & kepala & kepala & head & d'un & 170 & siapa & sapa & who & sai \\
\hline 114 & kering & keri & dry & k yi & 171 & sempit & sempet & narrow & sèmpit \\
\hline 115 & kiri & kighi & left & kIwah & 172 & semua & semua & all & lengk $\mathrm{p}$ \\
\hline 116 & kotor & ledah & dirty & dakI & 173 & suami & laki & husband & lakI' \\
\hline 117 & kuku & kuku & fingernail & kuku & 174 & sungai & sune & river & suNay \\
\hline 118 & kulit & kulet & skin & kulIt & 175 & ajam & tajem & sharp & tazem \\
\hline 119 & kuning & kune $\eta$ & yellow & kuni & 176 & ahu & dapet & know & tahu \\
\hline 120 & kutu & kutu & louse & kutu & 177 & tahun & taon & year & tahun \\
\hline 121 & ain & laen & other & lain & 178 & takut & takut & to fear & takut \\
\hline 122 & langit & lanet & sky & lanIt & 179 & ali & tali & rope & tali \\
\hline 123 & aut & laud & sea & laud & 180 & tanah & tanah & land & tanah \\
\hline 124 & lebar & luas & wide & lua & 181 & tangan & jari & hand & tanan \\
\hline 125 & leher & tenku? & neck & Jhiv & 182 & tarik & tarek & to pull & tarik \\
\hline 125 & ener & te $\eta$ ku! & neck & ilniy & 183 & ebal & tebal & thick & tèbal \\
\hline 126 & lelaki & jantan & man & & 184 & elinga & kupin & ear & talina \\
\hline 127 & empar & lempe & to throw & buan & 185 & elur & telor & egg & teluR \\
\hline 128 & icin & licin & smooth & mole mole & 186 & terbang & terba $\eta$ & to fly & layaný \\
\hline 129 & lidah & ilad & tongue (org & dilah & 187 & ertawa & ketawe & to laugh & tawa \\
\hline & & & $\begin{array}{l}\text { an) } \\
\text { a }\end{array}$ & (1) & 188 & tetek & susu & breast & daDa/susu \\
\hline 130 & ihat & teๆok & to see & tequk & 189 & tidak & tidek & no & buke(nN) \\
\hline 131 & lima & lime & five & lima & 190 & tidur & tenok & to sleep & tiDuR \\
\hline & & & & & 191 & tiga & tige & three & telu \\
\hline 132 & udah & ludeh & to spit & (dD)ahak & 192 & tikam & tikem & to stab & tikam \\
\hline 133 & lurus & lurus & straight & tusuk & 193 & tipis & tipis & thin & tIpIs \\
\hline 134 & lutut & lutot & knee & tuhud & 194 & tiup & tiýup & inflatable & tiýup \\
\hline 135 & main & maen & play & hayam & 195 & tongkat & tupkat & stick & tupked \\
\hline & & & & & 196 & waa & tua & old & tua \\
\hline 136 & makan & makan & eat & ma-kan & 197 & tulang & tule $\eta$ & bone & tula $\eta$ \\
\hline 137 & malam & malem & night & malem & 198 & tumpul & tumpol & dull & buDuh \\
\hline 138 & mata & mate & eye & mata & 199 & Ular & ular & snake & ular \\
\hline 139 & matahari & mataari & sun & sina & 200 & Usus & usus & guts & pèyut \\
\hline
\end{tabular}

\section{Penutup}

Dengan menggunakan 200

kata Swadesh dapat disimpulkan

bahwa pada umumnya kosa kata

BMDA memiliki kesamaan

dengan BMR. Perbedaannya

adalah pada pengucapan

denasalisasinya. Hampir setiap

kata diakhiri dengan bunyi sengau,

inilah ciri khas BMDA. Kosa kata 
yang ditemukan dalam penelitian ini tidak sama dengan BMR menjadi catatan penting karena peneliti yakin bahwa suatu saat kosa kata tersebut akan hilang secara perlahan, karena orang Akit sudah mengenal teknologi dan tidak merasa risau dengan hilangya perbendaharaan yang mereka miliki.

\section{Daftar Pustaka}

Dahlan, Saidat dkk. 1985. Pemetaan Bahasa daerah Riaudan Jambi. Jakarta: Pusat Pembinaan dan Pengembangan Bahasa Departemen Pendidikan dan Kebudayaan.

Djajasudarma. 2006. Metode Linguistik Ancangan Metode Penelitian dan Kajian. Bandung: PT. Eresco.

Hasan, Kailani. Mohd. Yunus R. Sugio H. Nurbaiti. 1983. Morfologi dan Sintaksis Bahasa Melayu Riau. Jakarta: Pusat Pembinaan dan Pengembangan Bahasa Departemen Pendidikan dan Kebudayaan.

La Ino. 2015. "Pemanfaatan Linguistik Historis Komperatif dalam Pemetaan Bahasa-Bahasa Nusantara". Retorika, Vol 1. No. 2. Link: www.researchgate.net/public
ation/314486382_Pemanfaat an_Linguistik_Historis_Kom paratif_Dalam_Pemetaan_B ahasa_Nusantara.

Mahsun. 2005. Metode Penelitian Bahasa: Tahapan Strategi, Metode, dan Tekniknya. Jakarta: Raja Grafindo Persada

Riswara, Yanti. 2015. "Inovasi Fonologis Denasalisasi dalam Isolek Bonai Ulakpatian". Madah, 6 (1). Http://ejournalbalaibahasa.id /index.php/madah/article/vie w/386/248.

Sudaryanto. 1990. Aneka Konsep Kedataan Lingual dalam Linguistik. Yogyakarta: Duta Wacana University Press.

1993. Metode dan Aneka Teknik Analisis Bahasa. Yogyakarta: Duta Wacana University Press.

Tambusai Azhary. 2016. "Tipologi Morfologis dan Struktur Argumen Bahasa Melayu Riau". Disertasi. Medan USU.

Widayati. 2018. "Hubungan Kekerabatan Bahasa Nias dan Bahasa Sigulai", Tutur,4 (1)APBL. 